Isabela Giardini a

Katia Soares da Poça ${ }^{\text {b }}$

Valéria dos Santos Pinto da Silva ${ }^{c}$

Marcia Sarpa de Campos Mello ${ }^{c, d}$

Karen Friedrich d,e

a Fundação Oswaldo Cruz, Instituto Nacional de Controle de Qualidade em Saúde, Programa de Pós-graduação Stricto Sensu em Vigilância Sanitária. Rio de Janeiro, RJ, Brasil.

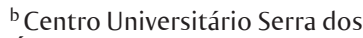
Órgãos. Graduação em Fisioterapia. Campus Quinta do Paraíso. Teresópolis, RJ, Brasil.

' Instituto Nacional de Câncer. Coordenação de Prevenção e Vigilância. Unidade Técnica de Exposição Ocupacional, Ambiental e Câncer. Rio de Janeiro, RJ, Brasil.

dUniversidade Federal do Estado do Rio de Janeiro. Instituto Biomédico. Rio de Janeiro, RJ, Brasil.

e Fundação Oswaldo Cruz, Escola Nacional de Saúde Pública, Centro de Estudos em Saúde do Trabalhador e Ecologia Humana. Rio de Janeiro, RJ, Brasil.

Contato:

Isabela Giardini

E-mail:

giardini.isabela@gmail.com

Apoio financeiro: Isabela Giardini foi bolsista de Mestrado da FAPERJ.

Os autores declaram não haver conflitos de interesses.

Os autores informam que o trabalho não foi baseado em dissertação/tese e que não foi apresentado em reunião científica.

\section{Vigilância sanitária em postos de revenda de combustíveis: aplicação de um modelo para integrar ações e promover a saúde do trabalhador}

\author{
Health surveillance in gas stations: application of a model to \\ integrate actions and promote worker's health
}

\begin{abstract}
Resumo
Introdução: o benzeno, composto encontrado na gasolina, é reconhecido como agente cancerígeno e tem sido objeto de controle em âmbito mundial devido aos seus efeitos agudos e crônicos à saúde humana. No Brasil, trabalhadores de postos de revenda de combustíveis (PRC) são expostos ao benzeno durante suas atividades ocupacionais. A Vigilância Sanitária, ao monitorar a exposição dos trabalhadores ao benzeno, pode avaliar os riscos e implementar estratégias para estabelecer um ambiente de trabalho mais seguro. Objetivo: suscitar a discussão sobre as ações da Vigilância Sanitária em postos de combustíveis baseada na aplicação do modelo Força-Motriz/Pressão/Situação/Exposição/Efeito/ Ação (FPSEEA). Método: realização de uma ampla revisão da literatura com a finalidade de obter as informações necessárias para construção e desenvolvimento da matriz proposta no modelo. Discussão: foi possível identificar as deficiências existentes nos diferentes níveis institucionais que possuem suas ações voltadas à proteção da saúde do trabalhador e propor ações para avançar na reflexão sobre o modelo de desenvolvimento, modos de produção e exploração de recursos. Também foram identificadas as possíveis ações da Vigilância Sanitária a serem aplicadas no ambiente ocupacional de PRC para eliminação ou redução dos riscos à saúde aos quais os trabalhadores estão expostos.
\end{abstract}

Palavras-chave: vigilância sanitária; benzeno; postos de combustíveis.

Recebido: 19/06/2015

Revisado: 09/03/2016

Aprovado: 24/03/2016

Keywords: health surveillance; benzene; gas station. 


\section{Introdução}

O avanço mundial da industrialização, incremento de novas tecnologias, processos produtivos, entre outros, gerou um grande impacto nas formas de trabalho, saúde e ambiente. No processo de globalização, a indústria química possui um papel muito importante, sendo a terceira maior atividade no mundo, empregando aproximadamente 10 milhões de pessoas ${ }^{1}$, além de ser um dos mais importantes e dinâmicos setores da economia brasileira. A indústria química é responsável pela produção de grande quantidade e variedade de insumos para todos os outros setores da economia, entre eles o setor do petróleo.

Dentre as atividades de comercialização petroquímica, encontram-se os postos revendedores de derivados de petróleo. No final de 2013, 38.893 postos operavam no país, sendo aproximadamente $41 \%$ destes localizados no Sudeste, com 13,5\% situados no estado do Rio de Janeiro ${ }^{2}$. No mesmo ano, os postos revendedores que operavam com bandeira branca no território nacional corresponderam a 40,7\% ${ }^{2}$. Cabe ressaltar que postos de bandeira branca são aqueles que optam por não exibir nenhuma marca comercial de nenhuma distribuidora ${ }^{2}$.

Os produtos que podem ser comercializados em um posto revendedor de combustíveis são: gasolina e suas variações, etanol, diesel e gás natural veicular (GNV). A gasolina é um combustível de composição complexa, consistindo de uma mistura de hidrocarbonetos voláteis e inflamáveis derivados do petróleo ${ }^{3}$. Dentre o grupo de substâncias presentes na gasolina, encontra-se o benzeno, um hidrocarboneto aromático com concentração controlada ${ }^{4}$.

A exposição ocupacional de trabalhadores ao benzeno pode ocorrer desde o processo de síntese de derivados de petróleo às atividades que possam liberar gases e vapores. Esses trabalhadores são, por exemplo, gerentes de postos de combustíveis, lubrificadores, lavadores de carros, trabalhadores de lojas de conveniência e frentistas. Todos estão expostos à fumaça de escapamentos automotivos e também ao contato direto com o benzeno presente na gasolina ${ }^{5}$. $O$ benzeno é considerado carcinogênico humano por diversas organizações, como a International Agency for Research on Cancer (IARC) $^{6}$, e pela United States Environmental Protection Agency (US-EPA) ${ }^{7}$. Devido a isso, diversas estratégias para reduzir o nível de exposição têm sido feitas para assegurar uma melhoria na qualidade de vida desses trabalhadores, como o aprimoramento da tecnologia dos meios de produção, a pressão das políticas de vigilância à saúde ocupacional, a tendência mundial de substituição do benzeno como solvente nos processos industriais e o avanço de metodologias aplicadas à análise de benzeno no $\mathrm{ar}^{8}$. Mesmo assim, trabalhadores de postos de combustíveis constituem um grupo de risco importante, embora pouco acompanhado no Brasil ${ }^{1}$.

As áreas componentes da Vigilância em Saúde (Vigilância Epidemiológica, Vigilância Sanitária e Vigilância Ambiental e do Trabalhador) devem atuar de forma integrada de modo a prevenir, da maneira mais efetiva, danos à saúde decorrentes da exposição a agentes químicos, físicos e biológicos. Suas ações têm por objetivo a observação e análise permanente da situação de saúde da população, destinando-se, mais diretamente, a controlar os riscos, determinantes e danos à saúde para proteger, prevenir e controlar doenças, e promover a saúde ${ }^{9,10}$.

Nesse sentido, a Portaria que definiu o Sistema Nacional de Vigilância Sanitária e sua abrangência ${ }^{11}$ definia, no seu artigo $3^{\circ}$, Vigilância Sanitária como o conjunto de ações, dentre outras, capaz de "exercer fiscalização e controle sobre o meio ambiente e os fatores que interferem na sua qualidade, abrangendo os processos e ambientes de trabalho, a habitação e o lazer"11. A Portaria ressalta, ainda, que cabe necessariamente à Vigilância Sanitária "as ações destinadas à promoção e proteção da saúde do trabalhador submetido aos riscos e agravos advindos dos processos e ambiente de trabalho".

A saúde do trabalhador constitui um campo da saúde pública e parte do princípio de que o trabalho é um determinante fundamental para o processo saúde-doença. Sendo assim, os principais constituintes que desencadeiam danos à saúde do trabalhador devem ser detectados e analisados para que medidas possam ser tomadas a fim de prevenir os riscos e garantir o nível mais elevado de bem-estar e qualidade de vida durante a jornada de trabalho ${ }^{12,13}$. É importante ressaltar que o conceito Saúde do Trabalhador não significa somente a ausência de doenças ocupacionais e acidentes de trabalho, mas também a transformação dos processos de trabalho para a eliminação de riscos pontuais que possam ocasionar agravos à saúde ${ }^{14}$.

Porém, na prática, observa-se o distanciamento das ações de Vigilância Sanitária sobre os riscos à saúde humana no ambiente de trabalho resultando em lacunas regulatórias que terminam por contribuir para a complexidade da determinação social do processo saúde-doença em certas atividades laborais, como as do campo petroquímico. Municípios e estados têm atuação mais direta sobre ambientes e serviços e, portanto, podem ser mais efetivos e transformadores das realidades dos territórios, assim como promover ações mais integradas entre as diferentes áreas da Vigilância em Saúde e propor ajustes, quando necessário, na estrutura organizacional de seus órgãos de saúde. Ações de Vigilância Sanitária são, portanto, necessárias nas diversas atividades relacionadas à saúde, podendo também ser exercidas sobre o ambiente de trabalho ${ }^{1}$. Por consequência, a Vigilância Sanitária teria como 
papel fundamental diminuir e/ou prevenir os riscos de exposição a substâncias que podem prejudicar a saúde dos trabalhadores durante sua jornada de trabalho.

Em virtude disso, este ensaio propõe compreender o cenário de risco químico em postos de revenda de combustíveis para identificar as áreas de atuação da Vigilância Sanitária voltadas à proteção dos trabalhadores nesses ambientes.

\section{Metodologia}

\section{Utilização do modelo Força Motriz/Pressão/Situação/ Exposição/Efeito/Ação (FPSEEA)}

Trata-se de um ensaio que propõe a aplicação de uma matriz Força Motriz/Pressão/Situação/Exposição/ Efeito/Ação (FPSEEA) ${ }^{15,16}$, para análise da situação de saúde dos trabalhadores de postos de combustíveis no Brasil, expostos a benzeno durante suas atividades ocupacionais.

A complexidade das ações da Vigilância em Saúde relacionada ao benzeno ultrapassa a ocorrência de doenças ou agravos à saúde relativos às substâncias químicas e envolve vários fatores intervenientes do processo saúde-doença ${ }^{17}$. Nesse sentido, foi escolhido o modelo FPSEEA, desenvolvido pela Organização Mundial de Saúde (OMS) $)^{15,16}$, por permitir a sistematização do complexo cenário de produção e exposição a riscos através da construção de uma matriz de análise da exposição ao benzeno em postos de revenda de combustível. A partir dessa ferramenta, pretendeu-se compreender as múltiplas relações de determinação, e em diferentes níveis de análise, desde o uso de tecnologias, seus processos, aos efeitos negativos sobre o ambiente e a saúde do trabalhador ${ }^{15,16} \mathrm{e}$ inspirar ações a serem tomadas em cada nível de complexidade, incluindo as de Vigilância Sanitária, para diminuir o risco de doenças em postos de revenda de combustível.

O modelo baseia-se na construção de uma matriz onde as ideias são apresentadas e organizadas em seis componentes: Força Motriz, Pressão, Situação, Exposição, Efeito e Ação, permitindo melhor compreensão de suas inter-relações. A construção da matriz ocorre através da inclusão dos dados referentes a cada componente da matriz e a sua correlação com os componentes seguintes. Pode ocorrer no sentido de "Efeitos" até "Força Motriz" e também da forma inversa, de "Força Motriz" até "Efeitos".

As Forças Motrizes (FM) são os representantes distais da saúde, relacionadas aos macrodeterminantes que possuem grande influência sobre as demais camadas do modelo. Estão ligadas ao modelo de desenvolvimento adotado pela sociedade, às condições socioeconômicas, políticas, culturais e ambientais que influenciam os processos de trabalho e levam aos consequentes efeitos à saúde ${ }^{18}$. As FM geram diversas Pressões (P) sobre o ambiente e contribuem para a alteração da situação ambiental e, consequentemente, para os efeitos à saúde ${ }^{17}$. A Situação $(S)$ representa a condição no ambiente ou no processo que é modificada pela Pressão (P), ou seja, que cria ou favorece o risco à saúde humana ${ }^{18}$ e que cria situações de risco. Diferente de Exposição (E), que descreve as diferentes vias e/ou agentes que levam à manifestação do efeito, sendo o ponto de intersecção entre a condição de saúde da população alterada pelas mudanças na situação ambiental (S), resultantes das pressões (P) e das forças motrizes (FM). Os Efeitos (E) são as manifestações clínicas resultantes da exposição $(\mathrm{E})^{17}$. Para cada componente do modelo são identificadas Ações (A) para conhecer, detectar e controlar os riscos à saúde, além de ser realizado um detalhamento segundo seus diferentes níveis ${ }^{17}$.

Para aplicar o modelo FPSEEA, foi realizada uma revisão ampla da literatura com a finalidade de obter as informações necessárias para a construção e desenvolvimento da matriz ${ }^{1,2,15,16,19-43}$. Os dados utilizados durante sua elaboração foram levantados a partir de uma busca de artigos científicos na base Medline (Medical Literature Analysis and Retrieval System), no portal Biblioteca Virtual em Saúde (BVS) e no Portal SciELO (Scientific Electronic Library Online). Para a efetuação da pesquisa, utilizaram-se para busca os seguintes descritores: "benzeno”, "saúde do trabalhador”, "exposição ocupacional”, "benzenismo", "aromatic hydrocarbons and service stations", "environmental and health indicators and DPSEEA". Também foram realizadas buscas de legislações relativas à saúde do trabalhador e Vigilância Sanitária, e de legislações referentes à utilização do benzeno em ambientes ocupacionais, além de documentos em bancos de dados públicos como: International Agency for Research on Cancer (IARC); Agência Nacional do Petróleo, Gás Natural e Biocombustíveis (ANP); Biblioteca Digital de Teses e Dissertações da USP, entre outros.

Os dados levantados foram organizados em níveis de complexidade, como recomendado pelo modelo FPSEEA. Para a construção dos três primeiros componentes da matriz (FM, P, S), foram levantadas e selecionadas pesquisas relacionadas com a exposição ocupacional ao benzeno e com a caracterização da substância, estudos que avaliaram a exposição concomitante ao benzeno e a outros solventes, e estudos e pesquisas que relacionavam agravos à saúde com a exposição ocupacional a outras substâncias químicas. Já para a construção dos demais componentes da matriz (E, E) foram selecionados, exclusivamente, estudos que avaliaram os efeitos sobre a saúde humana da exposição ao benzeno, uma vez que 
ele é classificado como agente cancerígeno. Foram excluídos os artigos que não estavam disponíveis para leitura na sua forma completa ou que não abordavam a exposição ao benzeno em postos de combustíveis.

Todos os dados apresentados e analisados foram coletados via internet, em bases de dados públicas, de livre acesso (sem necessidade de senhas nem de acessos com privilégio).

\section{Resultados}

O levantamento e a organização dos documentos encontrados na busca bibliográfica permitiram elaborar uma matriz FPSEEA (Quadro 1) sobre o cenário de risco da exposição ao benzeno presente na gasolina e seus efeitos sobre a saúde ocupacional dos trabalhadores de postos revendedores de combustível.

Quadro 1 Representação esquemática da matriz Força Motriz/Pressão/Situação/Exposição/Efeito/Ação (FPSEEA) relacionada à exposição ocupacional ao benzeno presente na gasolina de postos revendedores de combustiveis.

\begin{tabular}{|c|c|c|c|c|c|}
\hline Componente & \multicolumn{4}{|c|}{ Determinante } & Ações (A) \\
\hline $\begin{array}{l}\text { FORÇA MOTRIZ } \\
\text { (FM) }\end{array}$ & $\begin{array}{l}\text { Impacto que } \\
\text { a indústria do } \\
\text { petróleo tem em } \\
\text { nível nacional } \\
\text { e regional com } \\
\text { poucas iniciativas } \\
\text { para a substitutição } \\
\text { do benzeno }\end{array}$ & $\begin{array}{l}\text { Vulnerabilidade } \\
\text { dos } \\
\text { trabalhadores } \\
\text { frentistas dos } \\
\text { países em } \\
\text { desenvolvimento }\end{array}$ & $\begin{array}{l}\text { Dados sobre } \\
\text { as doenças } \\
\text { provocadas } \\
\text { pela exposição } \\
\text { ao benzeno, } \\
\text { no brasil, são } \\
\text { dispersos e raros }\end{array}$ & $\begin{array}{l}\text { As ações das comissões } \\
\text { (CNPBZ e CEBZ) que } \\
\text { discutem a exposição ao } \\
\text { benzeno são direcionadas } \\
\text { para empresas onde o } \\
\text { benzeno está presente } \\
\text { em maior quantidade, não } \\
\text { havendo ações específicas } \\
\text { nos postos revendedores } \\
\text { de combustíveis }\end{array}$ & $\begin{array}{l}\text { Aprimoramento da } \\
\text { tecnologia de produção } \\
\text { com a substituição do } \\
\text { benzeno como solvente; } \\
\text { estímulo à realização de } \\
\text { trabalhos epidemiológicos; } \\
\text { fortalecimento da } \\
\text { organização sindical; } \\
\text { inclusão dos postos de } \\
\text { revenda de combustíveis } \\
\text { como objeto das } \\
\text { comissões }\end{array}$ \\
\hline PRESSÃO (P) & $\begin{array}{l}\text { Ausência de } \\
\text { ações contínuas } \\
\text { e integradas de } \\
\text { vigilância com } \\
\text { a participação } \\
\text { sindical e de grupos } \\
\text { de trabalhadores } \\
\text { expostos }\end{array}$ & $\begin{array}{l}\text { Distanciamento } \\
\text { das ações } \\
\text { de vigilância } \\
\text { sanitária sobre } \\
\text { os riscos à } \\
\text { saúde humana } \\
\text { no ambiente de } \\
\text { trabalho }\end{array}$ & $\begin{array}{l}\text { Vulnerabilidade } \\
\text { na fiscalização } \\
\text { dos postos } \\
\text { quanto aos níveis } \\
\text { de exposição }\end{array}$ & & $\begin{array}{l}\text { Interlocução e atuação } \\
\text { integrada e ampliada; } \\
\text { atuação conjunta da } \\
\text { VISAT e VISA; aplicação } \\
\text { dos instrumentos legais; } \\
\text { necessidade de avanço nas } \\
\text { metodologias aplicadas à } \\
\text { análise de benzeno no ar }\end{array}$ \\
\hline \multirow[t]{2}{*}{ SITUAÇÃO (S) } & $\begin{array}{l}\text { Atividades que } \\
\text { liberam gases e } \\
\text { vapores }\end{array}$ & $\begin{array}{l}\text { Concentrações } \\
\text { de benzeno na } \\
\text { gasolina acima } \\
\text { da permitida na } \\
\text { legislação }\end{array}$ & $\begin{array}{l}\text { Cheirar a tampa } \\
\text { antes de iniciar } \\
\text { o abastecimento } \\
\text { para definir } \\
\text { o tipo de } \\
\text { combustível }\end{array}$ & $\begin{array}{l}\text { Uso de flanelas ao } \\
\text { abastecer e permanência } \\
\text { deste objeto com gasolina } \\
\text { próximo ao corpo }\end{array}$ & $\begin{array}{l}\text { Bombas mais seguras; } \\
\text { cumprimento da } \\
\text { legislação; ações de } \\
\text { educação e informação } \\
\text { em saúde a população } \\
\text { trabalhadora, circulante } \\
\text { e do entorno de postos }\end{array}$ \\
\hline & $\begin{array}{l}\text { "Puxar" (retirar) com } \\
\text { mangueira em caso } \\
\text { de abastecimento } \\
\text { com combustível } \\
\text { errado }\end{array}$ & $\begin{array}{l}\text { Comer durante } \\
\text { o trabalho } \\
\text { em posto de } \\
\text { combustível }\end{array}$ & & & \\
\hline EXPOSIÇÃO (E) & $\begin{array}{l}\text { Aspiração de } \\
\text { combustível }\end{array}$ & $\begin{array}{l}\text { Contato direto } \\
\text { da gasolina } \\
\text { com a pele }\end{array}$ & $\begin{array}{l}\text { Ingestão de } \\
\text { resíduos de } \\
\text { gasolina através } \\
\text { de alimentos } \\
\text { contaminados }\end{array}$ & Inalação de gases & $\begin{array}{l}\text { Exames periódicos } \\
\text { com intervalos } \\
\text { máximos de } 6 \text { meses; } \\
\text { monitoramento biológico }\end{array}$ \\
\hline \multirow[b]{2}{*}{ EFEITOS (E) } & Câncer & $\begin{array}{l}\text { Sinais e sintomas } \\
\text { neurológicos }\end{array}$ & $\begin{array}{l}\text { Sistema } \\
\text { hematopoiético }\end{array}$ & Edema pulmonar & \multirow{2}{*}{$\begin{array}{l}\text { Ações em saúde para } \\
\text { o manuseio adequado } \\
\text { dos equipamentos; } \\
\text { capacitação dos } \\
\text { peritos da previdência; } \\
\text { conselhos; sindicatos }\end{array}$} \\
\hline & $\begin{array}{l}\text { Danos imunológicos } \\
\text { e genéticos }\end{array}$ & Danos oxidativos & $\begin{array}{l}\text { Irritação das } \\
\text { mucosas } \\
\text { respiratórias } \\
\text { e oculares }\end{array}$ & Benzenismo & \\
\hline
\end{tabular}




\section{Força Motriz}

Levando em conta o pressuposto de que o componente FM são os representantes distais da saúde, correspondendo aos fatores que, em escala macro, influenciam os processos ambientais, durante o levantamento de dados na literatura científica foi possível identificar elementos que desempenharam tais influências. O primeiro ponto destacado como FM é a vulnerabilidade dos trabalhadores frentistas dos países em desenvolvimento, quando comparados aos países desenvolvidos. O modo de trabalho nos postos de revenda de combustíveis difere entre países com modelos de desenvolvimento diferentes, tornando os trabalhadores frentistas mais vulneráveis aos impactos à saúde causados pelo benzeno ${ }^{1}$. Devemos ressaltar também que os frentistas não são os únicos trabalhadores expostos nesse ambiente, em muitos postos de combustível há a oferta de diversos outros tipos de serviços, como lojas de conveniência e de peças automotivas, restaurantes, farmácias, padarias, entre outros. Logo, os trabalhadores das lojas e serviços também devem ser alvo das ações de Vigilância em Saúde.

Outro ponto importante categorizado como FM é o impacto que a indústria do petróleo tem a nível nacional e regional. O estado do Rio de Janeiro, por exemplo, no ano de 2012, foi o maior produtor de petróleo do Brasil, com 40\% da produção nacional ${ }^{2,19}$. Em 2012, a produção brasileira de derivados de petróleo foi de 120,3 milhões de $\mathrm{m}^{3}$; desse volume, 117,5 milhões de $\mathrm{m}^{3}$, 97,6\% do total, foram produzidos em refinarias, sendo o restante dividido entre centrais petroquímicas, unidades de processamento de gás natural e outros produtores ${ }^{2}$. Também há o fato de o benzeno ser utilizado nos dias de hoje em larga escala em diversos ambientes industriais, apesar de seu potencial carcinogênico plenamente conhecido, sendo poucos os esforços para a substituição deste solvente. Isso é justificado pelo fato de ser uma matéria-prima diversificada utilizada em todos os setores produtivos, desde a agricultura até o setor aeroespacial, com valor de uso e de troca extremamente lucrativo para o sistema econômico e produtivo ${ }^{20}$.

A elaboração de medidas institucionais para a redução da exposição do trabalhador ao solvente vai ao encontro de diversas dificuldades para articulação intrassetorial ao longo do tempo. Os dados sobre as doenças provocadas pela exposição ao benzeno, no Brasil, são dispersos e raros. Há uma dificuldade de estabelecimento de nexos causais e de notificações, pois em uma grande parte dos casos, as doenças relacionadas à exposição ocupacional ao benzeno costumam se manifestar distante do local onde foram contraídas, podendo ocorrer muitos anos depois. Além disso, a alta rotatividade, o fato de que o controle médico rigoroso dos trabalhadores ocorreu somente após a legislação de 1995, a inexistência de trabalhos epidemiológicos de busca ativa de casos junto a populações expostas ocupacionalmente, além da pouca cobertura dos serviços públicos de saúde para diagnóstico das doenças relacionadas ao trabalho e ao meio ambiente, são fatores que contribuem para que o conhecimento institucional continue fragmentado acerca das doenças ocupacionais relativas à exposição ao benzeno ${ }^{17}$. Por outro lado, outros trabalhadores expostos ao benzeno em postos de gasolina, além dos frentistas, podem estar ainda mais vulneráveis se não estiverem organizados em sindicatos que lutem para que sejam garantidas ações voltadas a sua saúde.

A Comissão Nacional Permanente de Benzeno (CNPBz) é um fórum tripartite de discussão, negociação e acompanhamento do Acordo do Benzeno ${ }^{21}$, que tem como objetivo acompanhar a implantação e o desenvolvimento do Acordo, propor e acompanhar estudos, pesquisas e eventos científicos para prevenção da exposição ocupacional ao benzeno, propor inclusões e alterações nos dispositivos legais que regulamentam a prevenção da exposição ocupacional ao benzeno ${ }^{22}$. O Ministério do Trabalho e Emprego (MTE), na Portaria $\mathrm{n}^{\circ}$ 371, de 26 de abril de 2013, fornece informações sobre o funcionamento das Comissões Estaduais e Regionais do Benzeno (CERBz) e dá a conformidade para seu funcionamento ${ }^{23}$. A comissão foi considerada como um componente da FM, pois o cotidiano dos postos de revenda combustíveis não está dentro das ações dessas comissões. As ações são direcionadas para empresas onde o benzeno está presente em maior quantidade, mas, como dito anteriormente, devido ao potencial tóxico do benzeno e sua ampla disseminação no ambiente, toda exposição à substância deve ser considerada e alvo de ações de mitigação, prevenção, fiscalização e controle.

\section{Pressão}

Os componentes da FM geram diversas pressões sobre o ambiente de trabalho. Isso pode ser exemplificado quando constatada a vulnerabilidade da fiscalização em postos de combustíveis, permitindo que sejam encontradas concentrações de benzeno na gasolina acima da permitida na legislação. A Resolução ANP $n^{\circ} 30$, de 29 de junho de 2015, estabelece as especificações para a comercialização das gasolinas automotivas no Brasil e define o máximo de 1,0\% para gasolina comum e premium tipo $\mathrm{C}$ no que se refere às concentrações de benzeno ${ }^{24,25}$. Porém, as informações de gasolina adulterada mostram teores muito acima de benzeno, sendo este fato preocupante, uma vez que os trabalhadores são expostos a concentrações muito acima da permitida na legislação ${ }^{26}$. 
Observou-se também que o Acordo Nacional do Benzeno, assim como os grandes estudos, foca em setores onde existem atividades de risco a grandes exposições de benzeno, como indústrias siderúrgicas, químicas e petroquímicas. Porém, como é um agente carcinogênico, toda exposição ocupacional ao benzeno deve ser acompanhada. Existe um grupo grande de trabalhadores que é exposto a essa substância durante as suas atividades laborais, mas a uma menor concentração, não menos tóxica para a saúde. Nesse grupo estão compreendidos os trabalhadores de postos revendedores de combustíveis, uma vez que o benzeno está contido na gasolina. Esses trabalhadores são expostos diariamente a concentrações de benzeno no ar, oriundo dos gases de escapamento automotivo, assim como estão expostos ao contato da substância na pele durante suas atividades ocupacionais ${ }^{27}$. A aplicação dos instrumentos legais deve, portanto, atingir todas as atividades que utilizam o benzeno em ambientes ocupacionais, como as atividades citadas anteriormente, que incluem trabalhadores dos serviços ofertados nos postos de gasolina.

Por sua vez, de maneira histórica, as ações de Vigilância em Saúde envolvem práticas de atenção ao doente e a adoção de mecanismos que controlem a disseminação de doenças. Entretanto, na atualidade já existe a preocupação com ações educativas, para que as ações de vigilância de fato sejam eficazes ${ }^{28}$. Nesse contexto, a Vigilância em Saúde do Trabalhador e/ou a Vigilância Sanitária deveriam atuar conjuntamente nas fiscalizações e ações de vigilância e monitoramento da exposição e dos efeitos tóxicos do benzeno em postos de combustíveis, levando informações sobre esses efeitos e educando os trabalhadores de modo a se "prevenirem" e diminuírem a exposição ao benzeno, embora o ideal devesse ser a não utilização de uma substância carcinogênica. A Vigilância Sanitária e seu poder de polícia podem ter papel fundamental na transformação da realidade dos trabalhadores expostos ao benzeno em postos de combustíveis.

\section{Situação}

As atividades que os trabalhadores realizam são, muitas vezes, resultados de regulações no processo de trabalho a fim de contemplar todas as tarefas aos quais são impostos, como a pressão por produção, a realização de diversas funções ou a redução do número de trabalhadores ${ }^{29}$.

O estudo realizado por D'Alascio et al. ${ }^{30}$ avaliou os hábitos ocupacionais dos trabalhadores de postos de combustíveis e mostrou que $30,7 \%$ dos trabalhadores que participaram de seu estudo tinham o costume de cheirar a tampa antes de iniciar o abastecimento, para definir previamente o tipo de combustível que seria utilizado, fato que aumenta a exposição inalatória, ou seja, através da respiração. Também demonstrou que 94\% utilizavam "paninhos" (flanelas) ao abastecer, favorecendo o contato com a pele e aumentando a exposição, devido à permanência de um objeto contaminado com gasolina próximo ao corpo. Além disso, 19\% dos entrevistados já aspiraram combustível com a mangueira, muitas vezes por realizar o abastecimento com o combustível errado, aumentando a exposição oral, ou seja, através da ingestão. Aliado a isso, o hábito de comer durante o trabalho em posto de combustível também torna a exposição oral maior. Nesse sentido, a elaboração de materiais informativos e de procedimentos de segurança em todo o ambiente dos postos de combustível podem ser objeto das ações de vigilância sanitária.

\section{Exposição}

Levando em conta o conceito de exposição adotado na matriz FPSEEA deste estudo, ou seja, o ponto de contato entre a condição de saúde e o ambiente, foi possível identificar os diversos momentos em que há exposição do trabalhador ao benzeno durante sua jornada de trabalho. A liberação do benzeno para o ambiente ocorre devido a fontes naturais e/ ou antropogênicas, através de emissões de gases de escapamento de veículos automotores, pela queima de combustíveis, pelas emissões como efluente industrial e pela fumaça de $\operatorname{cigarros}^{31}$. A exposição humana ao benzeno se dá principalmente pelo ar, sendo responsável por $99 \%$ do benzeno presente no corpo $^{35}$. Essa via de exposição é relevante não somente para os demais trabalhadores de um posto de gasolina, mas também para os motoristas profissionais e consumidores que frequentam esse serviço diária, semanal ou mensalmente. Outra forma de absorção de benzeno pelo trato respiratório ocorre pelo hábito que alguns trabalhadores adquirem de cheirar a tampa do tanque de combustível antes de abastecer ${ }^{32}$.

O benzeno como componente da gasolina, quando em contato com a pele, é absorvido e passa para a corrente sanguínea podendo provocar os mesmos danos ocasionados quando é inalado. A absorção de vapor de benzeno pela pele, no entanto, é muito baixa e não excede $1 \%$ do que é absorvido pela respiração na mesma condição ${ }^{33}$, mas, por se tratar de substância cancerígena, é significante do ponto de vista do risco à saúde. A absorção pode ser mais rápida no caso de pele com ferimento e o benzeno pode ser mais rapidamente absorvido se estiver presente em uma mistura como na gasolina ou como contaminante em solventes ${ }^{34}$. O hábito de usar flanelas durante o trabalho também favorece o contato com a pele e a exposição é maior devido à permanência de um objeto contaminado com gasolina próximo ao corpo. 
A exposição oral ocorre nos ambientes ocupacionais e está mais relacionada à ingestão acidental, através do hábito de comer, beber e fumar no ambiente de trabalho. No caso dos frentistas de postos de combustíveis, pode ocorrer a ingestão por práticas inadequadas como "puxar" a gasolina do tanque com a boca ${ }^{35}$.

\section{Efeitos}

Os Efeitos (E) são as doenças e agravos decorrentes da exposição. O conjunto de sinais, sintomas e complicações decorrentes da exposição aguda ou crônica ao benzeno é chamado de benzenismo. Quando a exposição se dá a altas concentrações, as manifestações clínicas podem ser agudas, com presença de sinais e sintomas neurológicos, ou crônicas, quando a exposição se dá por um longo período de tempo a concentrações baixas, com sinais e sintomas clínicos diversos, podendo ocorrer complicações a médio ou a longo prazo, localizadas principalmente no sistema hematopoiético ${ }^{36}$.

Em altas concentrações, o benzeno se mostra como irritante moderado das mucosas respiratórias e oculares, e quando aspirado pode levar a edema pulmonar. Também pode ocasionar danos ao sistema nervoso central e irritação na pele e nas mucosas ${ }^{35}$. Quanto aos efeitos crônicos, isto é, situações de exposição a pequenas concentrações de benzeno por longo período de tempo, podem ser observadas alterações hematológicas, com possibilidade de depressão das células sanguíneas; alterações na medula óssea, muitas vezes em casos irreversíveis de aplasia medular; alterações nos cromossomos, no sistema imunológico e vários tipos de câncer ${ }^{35,37,38}$.

Além disso, Ramadan, Osman e Mousa ${ }^{39}$ trataram das consequências imunotóxicas da exposição ocupacional de 60 trabalhadores frentistas, não fumantes, de postos de combustíveis. Foram dois grupos de estudo, sendo 30 expostos a gasolina por um período entre três e cinco anos, e 30 trabalhadores expostos por mais de cinco anos. O estudo permitiu concluir que houve um aumento no risco de imunotoxicidade e genotoxicidade nos trabalhadores expostos a esse combustível, risco esse proporcional ao tempo de exposição a gasolina.

Quando está associado a outros poluentes atmosféricos, o benzeno pode causar danos oxidativos ao DNA. Estudos realizados comparando a presença de tais danos entre crianças que residem em zonas urbanas com crianças residentes em zonas rurais mostram que as residentes em zonas urbanas, que sofrem maior exposição ao benzeno, principalmente de origem automotiva, e a outros poluentes ambientais, apresentaram mais casos de danos oxidativos ao DNA que as residentes em zonas rurais ${ }^{40}$. Ainda nessa linha de pesquisa, Chanvaivit et al. ${ }^{41}$ mostram que trabalhadores expostos ocupacionalmente ao benzeno apresentaram uma diminuição na capacidade de reparo das fitas de DNA, o que pode elevar o risco de efeitos genotóxicos, como crescimento celular irregular e casos de câncer. O seu efeito tóxico pode estar relacionado com sua ação direta ou pela ação de seus metabólitos. Sua toxicidade medular deve-se a sua capacidade de ligação de um ou mais de seus metabólitos a macromoléculas, como DNA e proteínas ${ }^{42}$. Espécies de oxigênio reativas (peróxido de hidrogênio, radical hidroxila, ânion superóxido) resultantes do metabolismo do benzeno podem danificar biomoléculas e levar a quebras nas fitas de DNA, micronúcleos e aberrações cromossômicas ${ }^{45}$.

Considerando os danos que podem ser provocados à saúde após a exposição ao benzeno, e que no Brasil ainda existem dificuldades no estabelecimento de medidas de proteção à saúde dos trabalhadores, as ações da Vigilância Sanitária tornam-se importantes ferramentas para minimizar os riscos aos quais esses trabalhadores são expostos diariamente. Deve-se ressaltar que o potencial de causar danos à saúde teoricamente torna o benzeno uma ameaça aos demais trabalhadores e consumidores que circulam em postos de combustíveis, mesmo que não existam estudos avaliando esse tipo de impacto.

É importante ressaltar que, mesmo com os avanços no conhecimento de sua toxicidade, a vigilância pode ser dificultada por fatores que combinam interesses econômicos, organização das formas de trabalho e a dependência internacional em relação a essa matéria-prima, que, sem perspectiva de banimento, fomenta movimentos contraditórios entre o desenvolvimento econômico e a proteção ao trabalho e à saúde dos trabalhadores.

\section{Proposta de ações}

Analisando a matriz é possível identificar lacunas como subsídio para definição de prioridades por tomadas de decisão e para avanço de pesquisas. Para cada componente identificado na matriz, propõe-se um conjunto de ações para a prevenção e a mitigação dos danos à saúde associados à exposição ao benzeno.

Como observado, no campo de FM, os problemas encontrados englobam áreas de interesses público e industrial. As medidas a serem adotadas para sanar as diferenças entre os países com níveis diferentes de desenvolvimento concentram-se no aprimoramento de novas tecnologias dos meios de produção e das ferramentas para o trabalho, como a utilização de bombas de combustível que funcionem de maneira mais segura para o trabalhador. Juan Carlos Viñas Cortez, professor da Universidade Federal da Paraíba (UFPB), desenvolveu um equipamento denominado Gasolimp, feito de esponja poliuretana, com a capacidade de 
absorver resíduos de combustíveis lançados durante o abastecimento. Segundo ele, a bomba de combustível elimina cerca de seis a oito gotas de gasolina a cada abastecimento que poderiam ser absorvidas pelos trabalhadores ocasionando efeitos danosos à saúde. A utilização do equipamento elimina os resíduos de combustível durante o abastecimento, reduzindo a exposição do trabalhador ${ }^{44}$.

O impacto econômico da indústria química a torna extremamente influente na definição de medidas regulatórias, definição de limites de exposição e ações de educação, como ilustra o assento que ocupa Comissão Nacional do Benzeno. Por isso, a participação de diferentes áreas e órgãos da Vigilância em Saúde é de fundamental importância para agregar diferentes olhares voltados à proteção dos interesses públicos. Também são de extrema relevância a participação sindical nos processos decisórios, devendo incluir também outros grupos de trabalhadores expostos (comerciantes, motoristas etc.). Ações de informação sobre os danos e as medidas de prevenção voltadas a todos os que circulam em postos de combustíveis são primordiais para a proteção dos indivíduos (trabalhadores e consumidores), mas também permitem o controle social e as denúncias de irregularidades.

Ações e políticas de acompanhamento da tendência mundial de substituição do benzeno como solvente nos processos industriais são fundamentais e devem ser cobradas pela população como um todo, pois é notório que existe pouco interesse na sua substituição pela indústria química, o que torna extremamente necessária a adoção de medidas pelos órgãos públicos para garantir a restrição da exposição ao benzeno em todas as fases do processo de produção e de manipulação, incluindo o produto acabado, para a proteção da saúde dos trabalhadores ${ }^{22}$.

Nesse contexto, a interlocução da Vigilância Sanitária e da ANP deve ser ampliada, uma vez que é função da Vigilância fiscalizar diretamente, ou mediante órgãos conveniados da administração pública, a atividade de revenda de combustíveis (Lei $n^{\circ}$ 9.847, de 28 de outubro de 1999), com o objetivo de garantir a qualidade e segurança dos produtos revendidos e verificar se a legislação está sendo cumprida ${ }^{26}$.

As áreas componentes da Vigilância em Saúde (Vigilância Ambiental, Epidemiológica e Sanitária) devem atuar de maneira integrada a fim de minimizar os riscos inerentes à exposição ocupacional ao benzeno. A Vigilância Ambiental possui um campo de atuação relacionado às substâncias químicas, como o benzeno. A sua forma de atuação se baseia nas ações sistemáticas e articuladas entre diferentes setores de governo e da sociedade civil, para detectar e controlar os fatores ambientais de risco à saúde da população exposta. A Vigilância Epidemiológica tem ampliado seu escopo nas últimas décadas para além das já tradicionais doenças transmissíveis e imunopreveníveis, englobando ações de prevenção e controle da população exposta a fatores de risco, inclusive para acidentes e doenças de trabalho. Portanto, a vigilância à população trabalhadora exposta ao benzeno entra no campo de atuações da Vigilância Epidemiológica ${ }^{45}$. As ações da Vigilância Sanitária destinam-se a eliminar, reduzir e prevenir os riscos a substâncias que podem prejudicar a saúde dos trabalhadores durante sua jornada de trabalho. A necessidade do estabelecimento da integração dos vários níveis do governo, das áreas da Vigilância em Saúde, do setor produtivo e dos demais órgãos públicos tenciona desenvolver ações articuladas e utilizar vários instrumentos e métodos para auxiliar o conhecimento, a detecção e o controle dos fatores de risco, e as doenças ou agravos à saúde da população trabalhadora exposta ${ }^{45}$.

É possível notar que, para sanar os problemas relacionados ao campo da Pressão, as principais ações voltam-se para a baixa aplicação dos instrumentos legais e à fiscalização dos órgãos públicos quanto ao cumprimento da legislação. Existem diversas leis, portarias e programas governamentais que voltam suas ações para a vigilância à saúde do trabalhador exposto ao benzeno. O grande problema é que, em muitos casos, essa legislação não é cumprida ou é voltada para locais onde a exposição ao solvente é em maior concentração. Entre os programas governamentais, vale citar o Programa de Vigilância em Postos de Combustíveis ${ }^{46}$, que objetiva realizar o controle do risco sanitário decorrente das atividades em postos, em que a Vigilância Sanitária atuaria através da aplicação de Roteiro de Inspeção Sanitária de Ambientes e Processo de Trabalho de Postos de Revenda de Combustíveis a Varejo (PRCV), e de Roteiro Básico para Avaliação de Áreas Contaminadas por Substâncias Perigosas. Além disso, visa implementar ações contínuas e integradas de vigilância tendo em vista tanto a proteção da saúde do trabalhador quanto da população do entorno dos postos de combustíveis. Suas ações demandam intersetorialidade, uma vez que integra desde a Vigilância Sanitária, propriamente dita, até os centros de vigilância específicos para a saúde do trabalhador, como os Centros de Referências Especializados em Saúde do Trabalhador (Cerest). Além disso, também demanda ações dos poderes públicos, como o Ministério do Trabalho (MT), Fundacentro e as Comissões Nacional e Estaduais do benzeno ${ }^{45,46}$.

Para controlar a exposição ocupacional ao benzeno no ar, foi estabelecida uma concentração máxima permitida, o chamado "valor de referência tecnológico (VRT)”. Trata-se de um valor de referência da concentração média ponderada pelo tempo, para uma jornada de 8 horas, obtida na zona respiratória ${ }^{27}$. 
O valor máximo estabelecido para empresas que integram o mesmo grupo de postos de combustíveis é de $1,0 \mathrm{ppm}^{17}$.

Especificamente para a proteção da saúde do trabalhador, além dos exames admissionais, devem ser feitos exames periódicos com intervalos máximos de seis meses, a fim de construir a série histórica de hemogramas do trabalhador. O monitoramento biológico deve ser realizado sempre que necessário para avaliar a exposição de trabalhadores em atividades de maior risco ou em situações onde houve algum descontrole ${ }^{21}$. Preconiza-se a análise do indicador biológico ácido trans,trans-mucônico na urina, que é um indicador sensível, ainda que com média especificidade $^{48,49}$. Executando essas e outras ações da legislação, é possível que se controle o risco dos trabalhadores expostos a benzeno.

Após a análise da situação de trabalho, nota-se que a exposição dos trabalhadores torna-se muito maior pelos hábitos que vão adquirindo conforme o tempo de trabalho. Uma das ações para prevenção da exposição ocupacional ao benzeno está no desenvolvimento de ações de educação aos trabalhadores, para que possam ser esclarecidos os riscos aos quais são submetidos diariamente e quais medidas de proteção devem ser tomadas por eles para minimizar essa exposição. A execução de estudos com envolvimento dos próprios trabalhadores, isto é, como sujeitos das pesquisas, permite maior entendimento e esclarecimento dos riscos ocupacionais, pois, além de ser uma estratégia de comunicação do risco, a informação ao trabalhador dos riscos inerentes a sua atividade é um direito fundamental que deve ser garantido. Estudos demonstraram a importância dessas ações ${ }^{20,50}$ que, contribuindo para o empoderamento da força de trabalho, tornam-nas capazes não somente de proteger a saúde individual, mas de reivindicar melhores condições de vida e de transformação da realidade do coletivo.

Existem diversas medidas que podem ser adotadas a fim de reduzir a exposição e os efeitos à saúde dos trabalhadores de postos de combustíveis em suas atividades diárias. Avaliar a qualidade das medidas de proteção adotadas para esses trabalhadores é um ponto muito importante, assim como o incentivo para adoção de novas tecnologias que reduzam essa exposição; ações em saúde para o manuseio adequado dos equipamentos do posto de combustível também foram propostas. Além do mais, o controle da concentração de benzeno presente na gasolina e o controle do benzeno no ar; ações educativas para os danos e possíveis danos à saúde dos trabalhadores; a capacitação dos peritos da previdência social para que as doenças ocupacionais possam ser mais facilmente detectadas; campanha informativa sobre a exposição do trabalhador ao benzeno junto aos sindicatos; cursos de atualização para o conselho de medicina, sobre as doenças ocupacionais, com materiais informativos que auxiliem no diagnóstico das alterações hematológicas decorrentes da exposição ao solvente, entre outros.

\section{Conclusões}

A utilização do modelo FPSEEA permitiu a organização das informações e a localização das possíveis ações da Vigilância Sanitária em postos revendedores de combustíveis, destacando a importância das ações integradas dos diversos setores da Vigilância em Saúde, pois cada uma das suas áreas componentes possui um papel diferente e fundamental para detectar, controlar, minimizar e, possivelmente, eliminar os riscos relativos à exposição ocupacional ao benzeno. Também permitiu delinear as deficiências encontradas nos diversos níveis institucionais que possuem suas ações voltadas diretamente à proteção da saúde do trabalhador e que, portanto, deveriam agir continuamente para a eliminação ou redução dos riscos à saúde dos trabalhadores de postos de combustíveis expostos ao benzeno, assim como os demais trabalhadores expostos em todo o ambiente do posto de combustível. Grande parte dos determinantes encontrados foi relacionada com a baixa aplicação dos instrumentos legais e com ações insuficientes de fiscalização dos órgãos competentes acerca do cumprimento da legislação. Esses são os determinantes básicos que influenciam em todos os níveis da matriz. Ao se aplicar corretamente a legislação e realizar a fiscalização do seu cumprimento, grande parte dos problemas encontrados neste estudo poderá ser minimizada, o que evidencia a importância das ações da Vigilância Sanitária para a proteção da saúde dos trabalhadores e redução dos riscos ao qual são expostos diariamente nas suas atividades ocupacionais.

Além disso, as ações de educação em saúde do trabalhador são extremamente importantes, já que, como discutido, a exposição ao benzeno torna-se maior quando associada a algumas adaptações no processo de trabalho. A Vigilância Sanitária também assume papel importante nessa etapa, pois no campo de suas ações encontra-se o fortalecimento das ações de educação em saúde.

Destacamos algumas das ações integradas, elaboradas a partir da aplicação da matriz FPSEEA e dispostas na última coluna da matriz:

a) Aprimoramento da tecnologia de produção com a substituição do benzeno como solvente;

b) estímulo à realização de estudos de cunho epidemiológico e popular, ou seja, envolvendo os trabalhadores como sujeitos da pesquisa; 
c) fortalecimento da organização sindical dos diferentes trabalhadores que circulam nos ambientes dos postos de combustíveis;

d) inclusão dos postos de revenda de combustíveis como objeto das Comissões;

e) interlocução e atuação integrada e ampliada das áreas de Vigilância Epidemiológica, Saúde do Trabalhador e Vigilância Sanitária;

f) necessidade de avanço nas metodologias aplicadas à análise de benzeno no ar;

g) desenvolvimento tecnológico de modo a tornar os equipamentos, como as bombas de combustíveis, mais seguros;

h) ampliar as ações de informação à população trabalhadora, circulante e do entorno dos postos sobre os danos e riscos decorrentes desses serviços;

i) garantir a realização de exames periódicos com intervalos máximos de seis meses, com a participação obrigatória dos trabalhadores em todo o processo de compreensão da importância e dos resultados das avaliações de saúde realizadas;

j) promover ações de capacitação dos peritos da previdência, dos conselhos profissionais e das organizações sindicais sobre os danos e riscos decorrentes da exposição em postos de combustíveis, incluindo ações mitigatórias, de prevenção e promoção da saúde nesses ambientes.

A matriz FPSEEA elaborada neste ensaio sistematiza o cenário de risco em postos de revenda de combustível. É possível observar que cada um dos componentes das quatro primeiras colunas da matriz aponta para a necessidade de ações em diferentes áreas da Vigilância em Saúde, ações que se complementam, conferindo uma abordagem sistêmica do cenário complexo de riscos químicos com potencial de causar danos crônicos graves e irreversíveis, como o câncer. Tais ações são apresentadas na última coluna. É possível observar que os componentes das duas primeiras linhas da matriz (Força Motriz e Pressão) apresentam determinantes centrais na produção do cenário de exposição aos riscos do benzeno em postos de combustível: lacunas de atuação integrada de diferentes setores e o papel do setor empresarial na produção de situações de vulnerabilidade e de pressão sobre os atores/setores envolvidos para a manutenção do estado de exposição a riscos.

A conformação da matriz, além de facilitar a visualização e a análise das possíveis inter-relações entre os componentes que a integram, permite formular ações articuladas e com eficácia ampliada. Tenham essas ações a forma de monitoramento ou de políticas públicas, a organização do cenário de riscos e sua análise integrada evita duplicidade de trabalho e lacunas de intervenção favorecendo, portanto, a implantação de medidas de prevenção de doenças e promoção da saúde no ambiente de trabalho que dependem, necessariamente, de uma atuação coordenada e permanente dos diferentes órgãos.

Frente a hegemonia da indústria petrolífera para a vida contemporânea, não só a ação intersetorial articulada deve ser promovida, mas também a avaliação do papel e do poder de decisão de cada setor interessado e promover a instância pública de coordenação de tais ações, onde a participação dos trabalhadores deve ser fortalecida.

\section{Contribuições de autoria}

Giardini I, Mello MSC, Friedrich K, Poça KS e Silva VSP participaram da elaboração e revisão crítica do trabalho. Giardini I, Mello MSC, Friedrich K e Poça KS contribuíram com a aprovação final do manuscrito. Giardini I e Mello MSC contribuíram substancialmente no projeto e foram responsáveis pelo delineamento, análise e interpretação de dados.

\section{Referências}

1. Costa DF. Prevenção da exposição ao benzeno no Brasil [tese]. São Paulo: Faculdade de Medicina Universidade de São Paulo; 2009. [acesso em 1 ago. 2014]. Disponível em: http://bit.ly/2psqTob.

2. Agência Nacional do Petróleo. Anuário estatístico brasileiro do petróleo, gás natural e biocombustíveis. Rio de Janeiro: ANP; 2013. [acesso em 29 jul 2014]. Disponível em: http://bit.ly/2q0KdWq.

3. Silva EF. Gestão ambiental dos postos revendedores de combustíveis no estado do Rio de Janeiro: uma avaliação crítica na visão ocupacional e ambiental da presença do benzeno na gasolina automotiva [dissertação]. Rio de Janeiro: Universidade Federal Fluminense; 2004.

4. Periago JF, Zambudio A, Prado C. Evaluation of environmental levels of aromatic hydrocarbons in gasoline service stations by gas chromatography. J Chromatogr A. 1997; 778(1-2): 263-8.

5. Martins LG. Avaliação da influência das emissões da indústria siderúrgica na exposição não ocupacional ao benzeno [dissertação]. Ouro Preto: Universidade Federal de Ouro Preto; 2009. 
6. International Agency for Research on Cancer. Iarc Monographs on the evaluation of carcinogenic risk to humans. Vol. 4. Lyon: World Health Organization, 1998. vol. 45.

7. United States Environmental Protection Agency. Carcinogenic effects of benzene: an update. Prepared by the National Center for Environmental Health, Office of Research and Development. Washington, DC. EPA/600/P-97/001F, 1998.

8. Coutrim MX, Carvalho LRF, Arcuri ASA. Avaliação dos métodos analíticos para a determinação de metabólitos do benzeno como potenciais biomarcadores de exposição humana ao benzeno no ar. Quím Nova. 2000;5(23):653-63.

9. Brasil. Secretaria de Vigilância em Saúde e Secretaria de Atenção a Saúde. Diretrizes nacionais de vigilância em saúde. Série pactos pela saúde. Brasília, DF: Ministério da Saúde; 2010.

10. Brasil. Ministério da Saúde. Portaria no 3.252, de 22 de dezembro de 2009. Aprova as diretrizes para execução e financiamento das ações de Vigilância em Saúde pela União, Estados, Distrito Federal e Municípios e dá outras providências. Diário Oficial da União, Brasília, DF, n. 245, p. 65-69, 23 dez. 2009. Seção 1.

11. Brasil. Ministério da Saúde. Portaria no 1565, de 26 de agosto de 1994. Definição do Sistema Nacional de Vigilância Sanitária e sua abrangência. Diário Oficial da União, Brasília, DF, 29 ago. 1994.

12. Mendes R, Dias EC. Da medicina do trabalho à saúde do trabalhador. Rev Saúde Públ. 1991;25(5):341-9.

13. Buss PM, Pellegrini Filho A. A saúde e seus determinantes sociais. Rev Saúde Coletiva. 2007;17(1):77-93.

14. Brito JC, Porto MFS. Processo de trabalho, riscos e cargas à saúde. Rio de Janeiro: Fiocruz; 1991.

15. Kjellström T, Corvalán C. Framework for the development of environmental health indicators. World Health Stat. 1995;48(2):144-154.

16. Corvalán CF, Kjellström T, Smith KR. Health, environment and sustainable development. Identifying links and indicators to promote action. Epidemiology. 1999;10(5):656-60.

17. Brasil. Ministério da Saúde. Secretaria de Vigilância em Saúde. Diretoria de Saúde Ambiental e Saúde do Trabalhador. Programa Nacional de Vigilância Ambiental em Saúde Relacionado a Substâncias Químicas. Brasília, DF: Ministério da Saúde; 2009. p. 34-42.

18. Sobral A, Freitas, CM. Modelo de organização de indicadores para operacionalização dos determinantes socioambientais da saúde. Saúde Soc. 2010;19(1):33-47.

19. Moreira C, Fernandes E, Gomes G, Dvorsak P, Heil T, Bastos VD. Potencial de investimentos no setor petroquímico brasileiro: 2007-2010. Brasília, DF: Banco Nacional do Desenvolvimento Econômico e Social; 2007. [acesso em 18 ago 2014]. Disponível em: http://bit.ly/2pwa3yx.
20. Corrêa MJM. A construção social do silêncio epidemiológico do benzenismo: uma história negada [dissertação]. Porto Alegre: Pontifícia Universidade Católica do Rio Grande do Sul; 2008.

21. Brasil. Ministério do Trabalho e Emprego. Acordo e legislação sobre o benzeno. São Paulo: Fundacentro; 1995.

22. Brasil. Ministério do Trabalho e Emprego. Secretaria de Segurança e Saúde no Trabalho. Portaria $\mathrm{n}^{0} 14$, de 20 de dezembro de 1995. In: Arcuri ASA, Cardoso LMN, coordenadores. Acordo e legislação sobre o benzeno: 10 anos. São Paulo: Fundacentro, 2005. p. 28-35. [acesso em 24 ago 2014]. Disponível em: http://bit.ly/2qKfsX4

23. Brasil. Ministério do Trabalho. Secretaria de Relações do Trabalho. Portaria $\mathrm{n}^{0} 371$, de 26 de abril de 2013. Dispõe sobre o funcionamento das Comissões Estaduais e Regionais do Benzeno. Diário Oficial da União, Brasília, DF, 29 abr. 2013. Seção 1.

24. Agência Nacional do Petróleo. Resolução no 29, de 25 de junho de 2015. Altera a Resolução ANP $\mathrm{n}^{\mathrm{O}} 40$, de 2013, que regula as especificações das gasolinas de uso automotivo. Diário Oficial da União, Brasília, DF, 30 jun. 2015.

25. Brasil. Ministério do Trabalho e Emprego. Portaria $\mathrm{n}^{\circ} 34$, de 20 de dezembro de 2001. Diário Oficial da República Federativa do Brasil, Brasília, DF, 27 dez. 2001. [acesso em 18 ago 2014]. Disponível em: http://bit.ly/2qKE1mL

26. Agência Nacional do Petróleo, Gás Natural e Biocombustíveis. Cartilha do posto revendedor de combustíveis. Rio de Janeiro, 2011. [acesso em: 1 ago. 2014]. Disponível em: http://www. sindicombustiveis-al.com.br/wp-content/ uploads/2013/08/cartilha-posto-revendedorcombustiveis.pdf

27. Rocha LP. Trabalhadores de postos de combustíveis: sujeitos expostos ao benzeno [dissertação]. Rio Grande: Universidade Federal do Rio Grande; 2012. [acesso em 2 nov 2015]. Disponível em: http://bit.ly/2q16IKW

28. Monken M, Batistella C. Vigilância em saúde. In: Pereira IB, Lima JCF. Dicionário da educação profissional em saúde. 2. ed. rev. ampl. Rio de Janeiro: EPSJV; 2009. [acesso em 12 jun 2015]. Disponível em: http://bit.ly/2r9HsDd

29. Trabalho Real. In: Dicionário da Educação Profissional em Saúde. Rio de Janeiro: Fiocruz/ Escola Politécnica de Saúde Joaquim Venâncio; 2009.

30. D’Alascio RG, Menegali M, Bornelli AS, Magajewsi F. Sintomas relacionados à exposição ocupacional ao benzeno e hábitos ocupacionais em trabalhadores de postos de revenda de combustíveis a varejo na região sul de Santa Catarina. Rev Bras Med Trab. 2014;12(1):21-9.

31. Martins LG. Avaliação da influência das emissões da indústria siderúrgica na exposição não ocupacional ao benzeno [dissertação]. Ouro Preto: Universidade Federal de Ouro Preto; 2009. 
32. Ministério da Saúde. Instituto Nacional de Câncer José Alencar Gomes da Silva. Vigilância do câncer relacionado ao trabalho e ao ambiente. 2. ed. Rio de Janeiro: Inca; 2012.

33. Hanke J, Dutkiwicz T, Piotrowski J. The absorption of benzene through human skin. Int J Occup Med Environ Heal. 2000;6(2):104-11.

34. United States Department of Labor. Medical surveillance guidelines for benzene. Washington DC: Osha. [acesso em 19 ago 2014]. Available from: http://bit.ly/2psKRIi.

35. Arcuri SAA, Costa DF, Possebon J, Kanasawa KC, Tardini LI, Constantino L et al. Efeitos da exposição ao benzeno para a saúde. São Paulo: Fundacentro; 2012. (Série Benzeno. Fascículo 1.)

36. Ministério da Saúde, Risco Químico: atenção à Saúde dos trabalhadores expostos ao benzeno. Brasília, DF: Ministério da Saúde; 2006. (Série A. Normas e Manuais Técnicos.)

37. International Agency for Research on Cancer. Monographs on the evaluation of the carcinogenic risk to humans. Overall evaluations of carcinogenicity: an updating of Iarc. Monographs Volumes 1 to 42. Lyon: Iarc; 1987.

38. United States Environmental Protection Agency. Iris: Toxicological review of benzene (Noncancer Effects). Washington, DC: EPA; 2002.

39. Ramadan MM, HS Osman, Mousa MEK. Chronic exposure to gasoline: evaluation of immunological and genotoxic effects among filling station workers. Mans J For Med Clinic Toxicol. 2000;8(2):85-98.

40. Buthbumrung N, Mahidol C, Navasumrit P, Promivijit J, Hunsonti P, Autrup $\mathrm{H}$ et al. Oxidative DNA damage and influence of genetic polymorphisms among urban and rural schoolchildren exposed to benzene. Chem BiolI Interact. 2008;172(3):185-94.

41. Chanvaivit S, Navasumrit P, Hunsonti P, Autrup $H$, Ruchirawat M. Exposure assessment of benzene in Thai workers, DNA-repair capacity and influence of genetic polymorphisms. Mutat Res. 2007;626(1-2):79-87.

42. Ruiz MA, Vassallo J, Souza CA. Hematologic changes in patients chronically exposed to benzene. Rev Saude Publ. 1993;27(2):145-51.

43. Moro AM, Charão MF, Brucker N, Durgante J, Baierle M, Bubols G et al. Genotoxicity and oxidative stress in gasoline station attendants. Mutat Res. 2013;754(1-2):63-70.

44. Dib AM, Oliveira LRZ, Dias OA, Torres ARR, Silveira NA. Avaliação da qualidade do sêmen e do estado de saúde de frentistas de postos de gasolina da cidade de Goiânia. Estudos. 2007;34(11-12):957-77.

45. Brasil. Vigilância Epidemiológica em Saúde Ambiental. Caderno de Vigilância Epidemiológica. São Paulo: Secretaria da Saúde; 2013. [acesso em 1 jun 2015]. Disponível em: http://bit.ly/2pDNUT3

46. Brasil. Programa de Vigilância em Postos de Combustíveis. Vale do Paraíba: Secretaria da Saúde, 2012. [acesso em 2 jun 2015]. Disponível em: http://bit.ly/2q3DB7u.

47. Brasil. Rede Nacional de Atenção Integral à Saúde do Trabalhador [online]. Brasília, DF: Renast, 2016. [acesso em 2 jun 2015]. Disponível em: http://bit. ly/2qot1Lg.

48. Ducos P, Gaudin R, Robert A, Francin JM, Maire C. Improvement in HPLC analysis of urinary trans,trans-muconic acid, a promising substitute for phenol in the assessment of benzene exposure. Int Arch Occup Environ Health. 1990;62(7):529-34.

49. Inoue O, Seiji K, Nakatsuka H, Watanabe T, Yin SN, Li GL et al. Urinary t,t-muconic acid as an indicator of exposure to benzene. In: Costa MFB. Estudo da aplicabilidade do ácido trans,transmucônico urinário como indicador biológico de exposição ao enzeno [tese]. Rio de Janeiro: Escola Nacional de Saúde Pública; 2001.

50. Augusto LGS. Estudo longitudinal e morfológico (medula óssea) em pacientes com neutropenia secundária à exposição ocupacional crônica ao benzeno [dissertação]. Campinas: Unicamp; 1991. 